Part of Journal of Research of the National Bureau of Standards, Volume 15, September 1935

\title{
AN EXTENSOMETER COMPARATOR
}

\section{By Ambrose H. Stang and Leroy R. Sweetman}

ABSTRACT

An extensometer comparator for the calibration of extensometers, compressometers, micrometer dials, and strain gages is described. The comparator has given satisfactory results in calibrating length-measuring instruments used for materials testing.

\section{CONTENTS}

199

II. Extensometer comparator

1. General

2. Frame $\ldots \ldots \ldots 9$

3. Adjustable crosshead 200

4. Spindles

5. Measuring apparatus

6. Method of calibrating an instrument 202

III. Conclusions

\section{INTRODUCTION}

In materials testing, loads and length changes are generally determined. Calibration of load-measuring devices can be accurately made using proving rings which are in turn calibrated by deadweights. ${ }^{1}$ The need for a satisfactory apparatus for calibrating the length-measuring instruments used in materials testing has resulted in the design of the extensometer comparator shown in figure 1. Extensometers, compressometers, dial micrometers, and strain gages having a gage length of from $1 / 4$ to 24 in. can be calibrated on the comparator.

\section{EXTENSOMETER COMPARATOR}

\section{GENERAL}

The extensometer comparator shown in figure 1 consists essentially of a rigid frame, an adjustable crosshead, and the apparatus for length measurements.

\section{FRAME}

The main parts of the frame are the upper and lower yokes and the side tubes. The upper yoke a is a structural steel $\mathrm{H}$-section; the lower yoke b is a portion of a structural steel $\mathrm{H}$-section with 1

1 L. B. Tuckerman, Herbert L. Whittemore, and Serge N. Petrenko, A new deadweight testing machine of 100,000 pounds capacity, BS J. Research 4, 261 (1930) RP147. 
flange cut off. The side tubes c are seamless drawn-steel tubing. The connections between these parts are made by the 4 solid-steel plugs d, bolted to the webs of the crossheads. One end of the plug is slotted, making a pressed fit over the web. The other end, a cylinder of smaller diameter, is a pressed fit with the machined inside surface of the tube end. The outside surfaces of the tubes were machined concentric with the inside surfaces. The tubes are parallel, permitting the adjustable crosshead e to be moved along the tubes without binding.

\section{ADJUSTABLE CROSSHEAD}

The sides of the adjustable crosshead are structural-steel channel sections with the flanges toward each other. The flange edges are machined to fit the tubes of the frame. The crosshead may be placed at the proper distance from the measuring end, according to the gage length of the instrument to be calibrated, and locked in position by tightening the handles $\mathrm{f}$ on the bolts holding the channels together.

\section{SPINDLES}

Both the measuring end and the adjustable crosshead are provided with spindles, coaxial with each other, to which the instrument may be fastened. If the instrument is a hand strain gage, the instrument points may be inserted in gage holes on a plane through the axis of the spindle. Fixtures for other types of length-measuring devices may be attached to the ends of the spindles by the type of coupling $g$ shown in figure 2 at the end of movable spindle $h$.

Spindle $j$ (fig. 1) in the adjustable crosshead is also adjustable with respect to the crosshead for a distance of about 6 in. and may be locked in position. This feature makes it unnecessary to move the entire crosshead for small changes in gage length. Accuracy in setting the relatively heavy crosshead for different gage lengths is therefore unnecessary.

\section{MEASURING APPARATUS}

A diagrammatic view of the measuring end of the comparator is shown in figure 2. The movable spindle in this end is moved relative to the fixed spindle in the adjustable crosshead by means of handwheel $\mathrm{j}$ threaded on the spindle and actuated by worm $\mathrm{k}$ attached to the frame. The worm may be disengaged for rapid movement of the spindle. The threaded portion of the spindle has 20 threads per inch, the circumference of the wheel 360 teeth. One turn of the worm causes a movement of the spindle of $0.00014 \mathrm{in}$. An angular motion of about $260^{\circ}$ in the worm moves the spindle $1 / 10,000$ in. Relatively sensitive adjustments may, therefore, be made. The movable spindle is prevented from rotating by torque arm 1.

Compression spring $\mathrm{m}$, located between the frame and auxiliary disk $\mathrm{n}$ threaded on the movable spindle and keyed by pins $o$ to the handwheel, takes up backlash in the threads. This feature allows the comparator to be used in any position, horizontal, vertical, or inclined. The position of the movable spindle does not depend on gravity. A force of about $70 \mathrm{lb}$ on the spindle produced by the spring is sufficient to prevent motion of the spindle due to forces set up by the mechanism of the instrument to be calibrated. Ball 


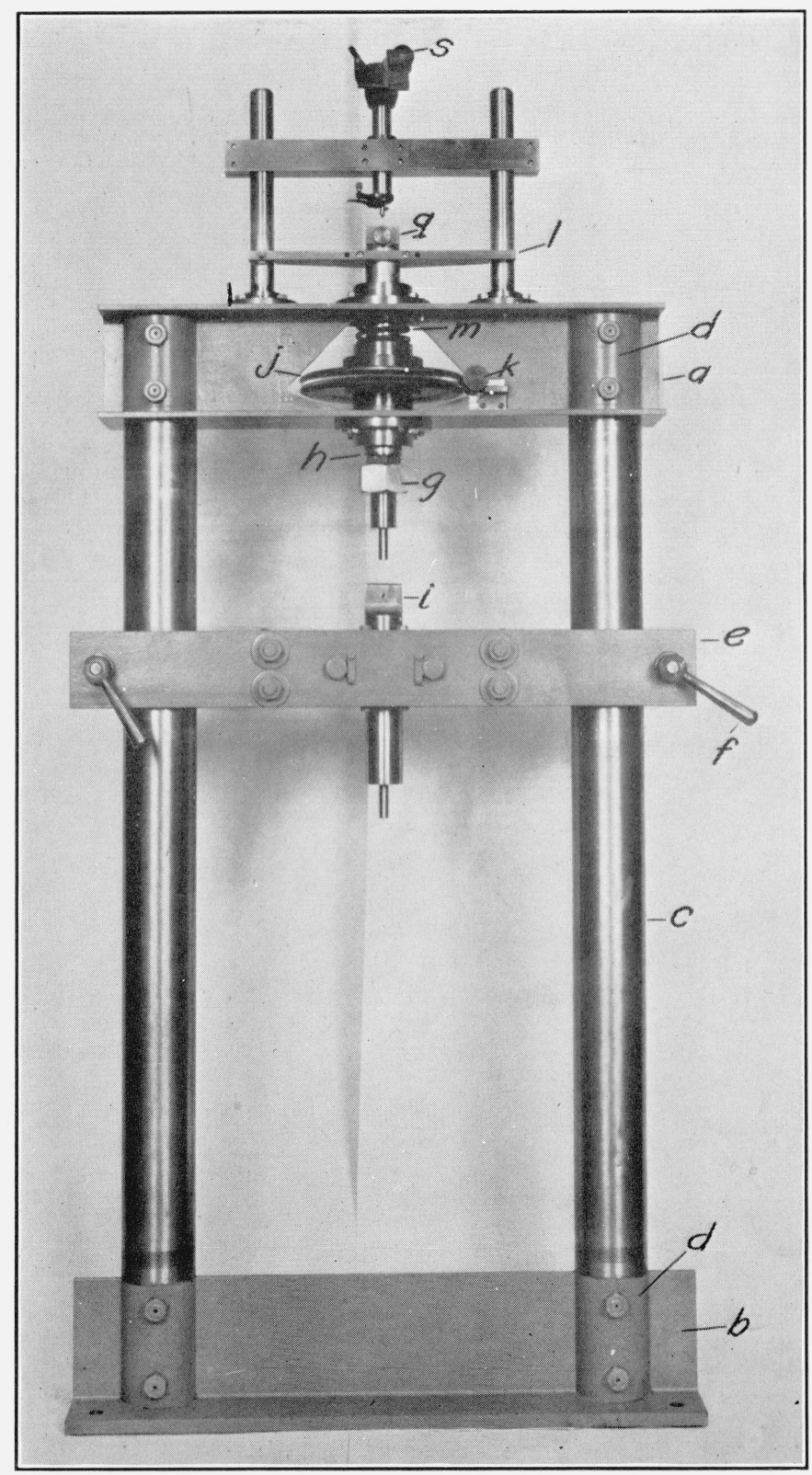

Figure 1.-Extensometer comparator. 
thrust bearings $\mathrm{p}$, located between the frame and the spring and between the frame and the handwheel, are provided with dust covers.

The upper end of the movable spindle is provided with vise $q$, in which a standard gage block $\mathrm{r}$ is clamped. Indicator $\mathrm{s}$ is attached

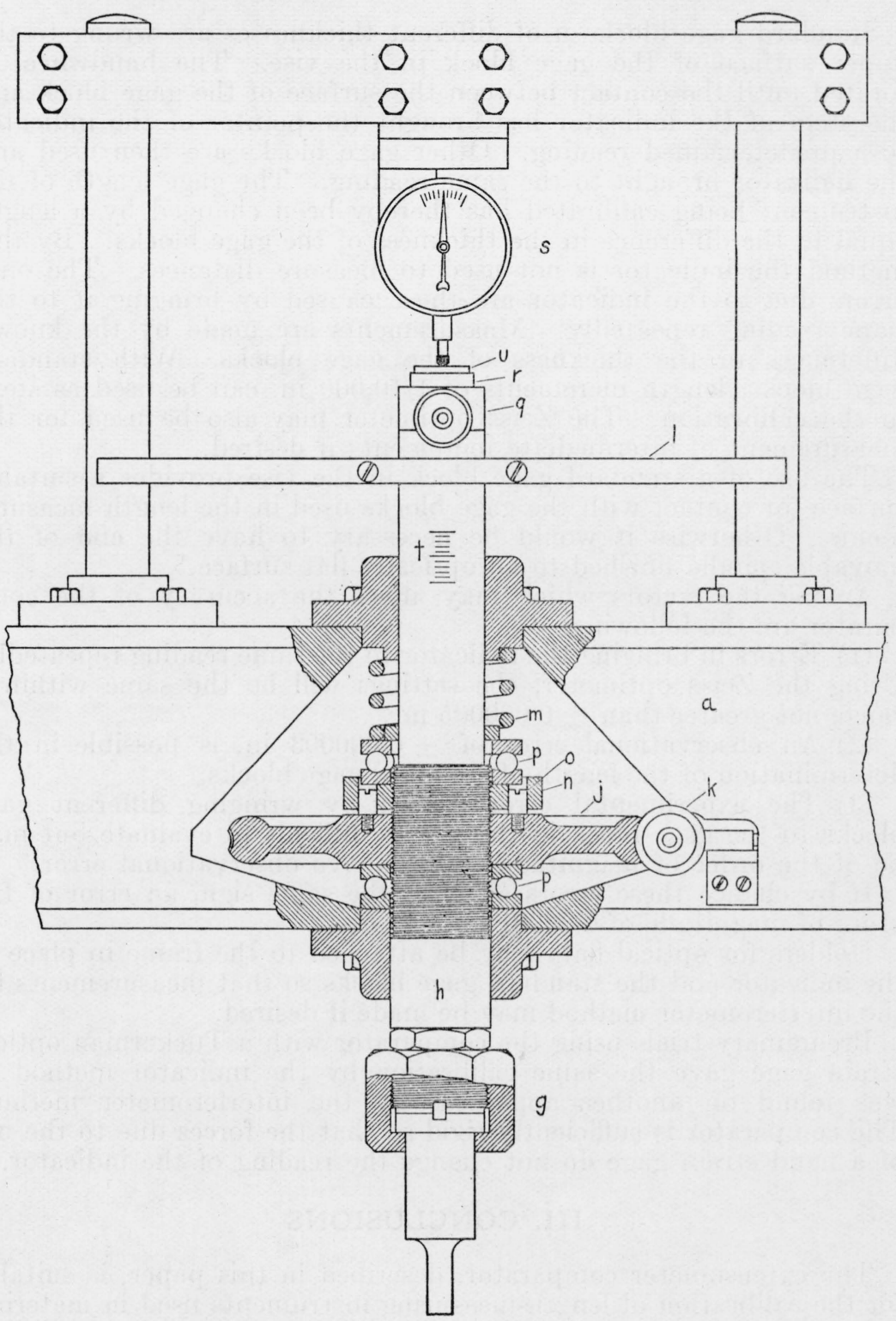

Figure 2.-Measuring end of extensometer comparator.

to the upper crosshead. The indicator shown in figure 1 is a Zeiss optimeter and in figure 2 a dial micrometer.

The range of the extensometer comparator is $1 \mathrm{in}$. Scale $t$, graduated in tenths of an inch, is on the surface of the movable spindle. 
The reading of this scale indicates whether the movable spindle is or is not in the proper working position.

\section{METHOD OF CALIBRATING AN INSTRUMENT}

Standard gage blocks $u$ of different thicknesses are wrung to the upper surface of the gage block in the vise. The handwheel is rotated until the contact between the surface of the gage block and the stem of the indicator has brought the pointer of the indicator to a predetermined reading. Other gage blocks are then used and the indicator brought to the same reading. The gage length of the instrument being calibrated has thereby been changed by a length equal to the difference in the thickness of the gage blocks. By this method the indicator is not used to measure distances. The only errors due to the indicator are those caused by bringing it to the same reading repeatedly. Measurements are made by the known differences in the thickness of the gage blocks. With standard gage blocks, length increments of $1 / 10,000$ in. can be used as steps in the calibration. The Zeiss optimeter may also be used for the measurement of intermediate increments if desired.

The use of a standard gage block in the vise provides a suitable surface for contact with the gage blocks used in the length measurements. Otherwise it would be necessary to have the end of the movable spindle finished to an optically flat surface.

Among the factors which may affect the accuracy of the comparator are the following:

(1) Errors in bringing the indicator to the same reading repeatedly. Using the Zeiss optimeter, the settings will be the same within a range not greater than \pm 0.000005 in.

(2) An observational error of \pm 0.000003 in. is possible in the determination of the length of standard gage blocks.

(3) The experimental error caused by wringing different gage blocks to the gage block in the vise is difficult to evaluate but may be of the order of magnitude of the above observational error.

If by chance these errors all have the same sign, an error of the order of magnitude of 0.00001 in. may exist.

Holders for optical flats may be attached to the frame in place of the indicator and the standard gage blocks so that measurements by the interferometer method may be made if desired.

Preliminary trials using the comparator with a Tuckerman optical strain gage gave the same calibration by the indicator method as was found on another apparatus by the interferometer method. The comparator is sufficiently rigid so that the forces due to the use of a hand strain gage do not change the reading of the indicator.

\section{CONCLUSIONS}

The extensometer comparator, described in this paper, is suitable for the calibration of length-measuring instruments used in materials testing. The length measurements are made, using standard gage blocks of known thickness. The comparator may be used in any position. Forces exerted by the instrument being calibrated do not affect the accuracy of the calibration. 
The extensometer comparator was designed by members of the Engineering Mechanics Section and built in the Bureau instrument shop. Valuable suggestions and assistance in the design were given by D. R. Miller, Chief, Gage Section; by members of his staff; and by H. J. Kaiser, who built the comparator.

The principle of the design, that of using standard gage blocks with an indicator for the calibration of extensometers, has been used in the Laboratory of Theoretical and Applied Mechanics at the University of Illinois by Prof. H. F. Moore.

Washington, June 29, 1935. 